crease in the free energy of ionization is a minimum, and the stability toward rearrangement is a minimum.

9. Many rearrangements with reaction are due to the fact that a free radical cannot exist, and after certain atoms or groups have been eliminated the rery unstable radical resulting undergoes a readjustment of the atoms present so as to maintain the quadrivalent nature of carbon and produce a substance more stable toward rearrangement.

IO. A schematic review of the field of molecular rearrangements of carbon compounds is given by Table $V$, and Table VI gives illustrations of the classes of rearrangements designated in Table V.

The author wishes to thank Dr. W. A. Noyes, of the University of Illinois, for his kind suggestions and criticisms of this paper and also Dr. W. C. Bray, of Massachusetts Institute of Technology, for his kind suggestions regarding Section 4 .

[Contribution From the Bureau of Chemistry; U. S. Dept. of Agriculture.]

\title{
THE INVERSION OF CANE SUGAR BY INVERTASE. VII. THE EFFECT OF ALCOHOL ON INVERTASE.
}

\author{
By C. S. HUdSON AND H. S. PAINE. \\ Received July II, Igro.

\section{Purpose of the Investigation.}

A knowledge of the action of alcohol on invertase is of practical importance for two reasons: first, alcohol is naturally present during the fermentation of cane sugar by yeast and the invertase of the yeast is thus normally in the presence of weak alcohol; and, second, alcohol is often used, though generally with little success, to prepare the enzyme in a solid form by precipitation from an aqueous extract of yeast. In order to learn what influence alcohol of different strengths has on invertase, the following investigation was made. The results show that the influence is exceedingly great and that it consists in three distinct actions, namely, an inactivation, a permanent destruction, and a precipitation of the enzyme. These actions will be described in the order named.

The Inactivation of Invertase by Alcohol.--The activity of purified invertase in inverting cane sugar dissolved in various strengths of ethyl alcohol was measured at $30^{\circ}$ by the usual method. Care was taken to have sufficient acetic acid in the solutions to insure that the maximum activity of the enzyme was attained, and the solutions were made alkaline at the end of the experiment to stop the enzymatic action and complete the mutarotation. The alcohol used was Squibb's or Baker's absolute alcohol and the concentrations are expressed as volume per cent. The activities are recorded in Table I as the velocity coefficients of the inversion, using minutes and decimal lagarithms and multiplying by 
10,000 to avoid decimals. The results are also expressed graphically in Fig. I.

It is apparent that alcohol has a strong inactivating action on invertase even when the alcohol is dilute. The destruction of invertase by alcohol does not take place below about 20 per cent., as will be shown under the following caption, but the activity of the enzyme is markedly lowered by even a few per cent. of alcohol. The figure shows that the relation

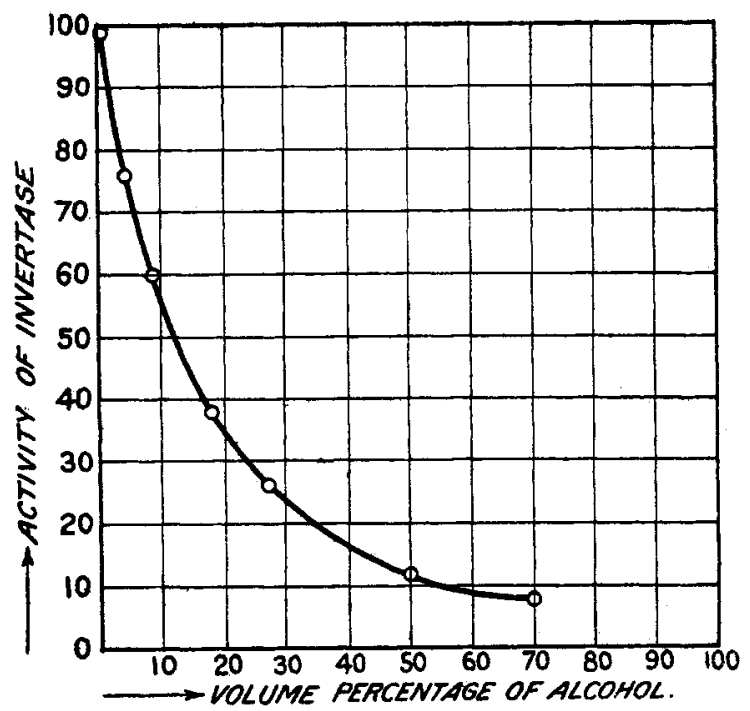

Fig. 1.-The influence of alcohol on the activity of invertase.

between alcoholic strength and activity is not proportionality but may be represented as a logarithmic or hyperbolic function. On account of the fact that rapid destruction of the enzyme takes place in solutions above 30 per cent. alcoholic strength it is not possible to measure the activity of invertase in this region by the usual method; the theory of the modified procedure which has accordingly been used to measure the activity in 50 and 70 per cent. alcohol is given on page 1355 and the values which were found are included in the table and figure.

The inactivation of invertase by alcohol was noticed by O'Sullivan and Thompson, ${ }^{1}$ and they state that the inactivation by alcohol is "in direct proportion with the amount present. Five per cent, alcohol decreases the speed of the reaction by about one-half." The results here given are somewhat different in detail from those quoted, because we have measured the inactivation for higher strengths of alcohol than were used by the previous investigators. It will be noticed that our results also

' J. Chem. Soc., 27, 927 (1890). 
show almost a linear relation between activity and alcohol strength for weak alcoholic solutions.

Table I.-Activity of Purified Invertase in Aqueous Alcohol.

(Temperature $30^{\circ}$. Concentrations: Aqueous alcohol containing cane sugar 0.2 normal, and acetic acid 0.02 normal; roo cc. of this mixture were added to ro cc. of purified invertase solution.)

$\begin{array}{ccc}\begin{array}{c}\text { Concentra- } \\ \text { tion of alco. } \\ \text { hol (volume } \\ \text { percent.). }\end{array} & \begin{array}{c}\text { Activity } \\ \text { invertase } \\ \mathrm{K}_{1}(10,000)\end{array} & \begin{array}{c}\text { Percentage } \\ \text { activity. }\end{array} \\ 0.0 & 80.0 & 100 \\ 4.3 & 61.0 & 76 \\ 9.1 & 48.0 & 60 \\ 18.2 & 30.0 & 38 \\ 27.3 & 21.0 & 26 \\ 50.0 & 8.8 & 1 \mathrm{I} \\ 70.0 & 6.4 & 8\end{array}$

The Destruction of Invertase by Alcohol.-The measurements of the destruction of invertase by alcohol were made by the method previously used in studying the destruction of the enzyme by acids and alkalies. ${ }^{1}$ The rate of the destruction follows the course of unimolecular reactions, as is shown by the following experiment. The value of the velocity coefficient of the unimolecular formula, $k_{2}$, remains constant within the errors of experiment during the course of the destruction.

TABLE II.-UNImolectlar ORDER OF THE DESTRUCTION OF INVERTASE BY ALCOHOL. (Temperature $30^{\circ}$. Alcohol 20 per cent. by volume. Maximum activities were measured.)

Time.

0

15

30

45

75

105

I 65
Activity of invertase $\left[k_{2}(10,000)\right]$.

8.98

8 . II

$7 \cdot 33$

6.54

$5 \cdot 41$

4.66

4. 13
Velocity coefficient

$\left(k_{n}\right)$.

.....

0.00295

0.00294

0.00306

0.00293

0.0027 I

0.00204

Average, 0.00277

The rates of destruction of invertase which were found in various strengths of alcohol are recorded in Table III, the values of $k_{2}$ being expressed in minutes and decimal logarithms and multiplied by $I, 000$ to avoid decimals. The results are also shown graphically in Fig. 2.

The rate of destruction changes most peculiarly with the strengths of the alcohol, reaching a pronounced maximum at about 50 per cent. Presumably the protective action of strong alcohol is due to its precipitating the invertase, or some other substance whose precipitation protects the

1 This JourNaL, 32, 778 (I910), 
TaBle III,-Rates OF DESTRUCrion OF INVERTASE BX ALCOHOL.

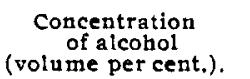

o

I0

20

30

40

45
Rate of destruction
$\quad\left[k_{2} \times(1,000)\right]$

\begin{abstract}
$\circ$
\end{abstract}
0

3

44

260

487
Concentration

volume per cent)

50

55

60

70

80

90
Rate of destruction

$\left[k_{2} \times(1,000)\right]$.

invertase, as a visible precipitation begins at or near the strength of 50 per cent., at which the maximum of the curve falls and the protective action begins. If the curve to the left of the maximum is alone regarded as the curve of the destruction in solution, it is noticed that it is very similar to the curve for the destruction of the enzyme by acids and alka-

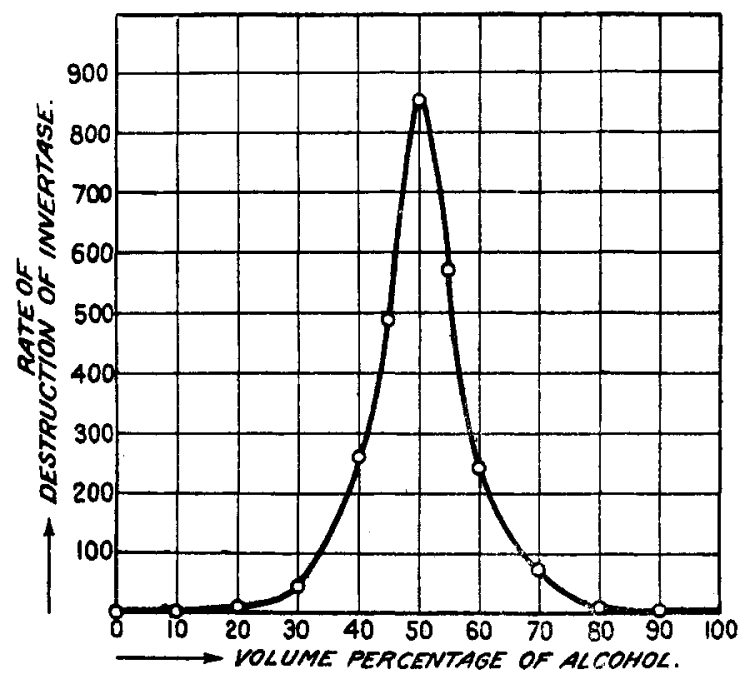

Fig. 2.-The destruction of invertase by alcohol.

lies. ${ }^{1}$ It appears, therefore, that the destruction by alcohol in homogeneous solution is due to a decomposition of the invertase similar to the hydrolytic decompositions that are presumably the cause of the destruction by acids and alkalies. The practical application of the results on alcoholic precipitation is given on page 1356 .

The Action of Cane Sugar in Preventing the Destruction of Invertase.In order to learn whether cane sugar protects invertase from destruction by alcohol, the rate of destruction in a 0.2 normal solution of cane sugar in 50 per cent. alcohol was measured at $30^{\circ}$ by the method already described. A correction was applied for the rotation of the sugar in the

: This Journal, 32, 779. 
samples as they were removed to test their activities. The method of preparing the mixture of cane sugar, aqueous alcohol, invertase, and acetic acid is shown in the description of the experiment recorded in Table $V$; the results on the rate of destruction are given in Table IV:

Table IV.--Rate of Destruction of Invertase in 50 Per cent. Alcohol Containing 6 Per cent. of Cane Sugar.

$\begin{array}{ccc}\text { Time } & \text { Activity of sample } & \left(k_{1}\right) \\ \text { Minutes. } & 0.00049 & \text { velocity coefficient } \\ 0 & 0.00024 & \ldots \\ 30 & 0.00016 & 0.010 \\ 60 & & 0.008 \\ & & \text { Average, } 0.009\end{array}$

The rate of destruction is far less than that shown for 50 per cent. alcohol in Table III, namely $0.85^{\circ}$. The cause of this difference can lie only in the fact that cane sugar was not present in the latter experiments. Several other experiments have given results agreeing with these in showing that cane sugar exerts a very strong influence in protecting invertase from destruction by alcohol. O'Sullivan and Tompson ${ }^{1}$ have shown that cane sugar protects invertase from destruction by hot water, and it is well known among distillers that diastase is not so easily destroyed by hot water, if maltose is in the solution; it is then an analogous fact that cane sugar protects invertase from the action of alcohol. The most plausible explanation is that these sugars combine with the enzyme, and the resulting compound is not so easily attacked by alcohol or hot water.

\section{Theory of the Rate of Inversion of Cane Sugar during the Destruction of the Invertase.}

The rate of inversion of cane sugar by invertase in dilute solution follows the unimolecular order, and it has just been shown that the rate of destruction by alcohol does the same. If invertase is added to a solution of cane sugar in aqueous alcohol of a strength which destroys the enzyme, there occur two simultaneous reactions, the inversion of the cane sugar and the destruction of the invertase. The theory of these dependent or coupled reactions is as follows: At constant temperature start with a solution containing $A$ gram molecules of cane sugar per liter and $I$ units of invertase. After the lapse of $t$ minutes let there be in the solution $i$ units of invertase and $(A-x)$ gram molecules of cane sugar. The rate of destruction of the invertase is

$$
-d i / d t=k_{2} i
$$

in which $k_{2}$ is the velocity coefficient of the destructive reaction. The integral of Equation $\mathrm{I}$ under the condition that $i=I$ when $t=O$ is

$$
i=I e^{-k_{\mathrm{g}} t}
$$

${ }^{1} J$. Chem. Soc., 57, 900 (1890). 
The rate of inversion of the cane sugar is

$$
d x / d t=k_{1}(A-x) i / I=k_{1}(A-x) e^{-k_{2} t},
$$

where $k_{1}$ is the velocity coefficient of the inversion when $I$ units of invertase are present. The integral of Equation 3 under the condition that $x=O$ when $t=O$ is

$$
\log A / A-x=k_{1} / k_{2}\left(I-e^{-k_{2} t}\right) .
$$

Equation 4 has been used in finding the velocity of inversion of cane sugar by invertase $\left(k_{1}\right)$ in 50 per cent. alcohol. A mixture of $600 \mathrm{cc}$. of 0.2 normal cane sugar solution in 55 per cent. alcohol (which was also 0.02 normal with respect to acetic acid) with $60 \mathrm{cc}$. of dialyzed invertase solution was kept at $30^{\circ}$ and the progress of the inversion measured polarimetrically from time to time, the samples being made alkaline before each reading of the rotation. In Table $V$ the rate of this incomplete inversion of cane sugar by invertase in $5^{\circ}$ per cent. alcohol is recorded. The quantity of cane sugar present $(A)$ is expressed in degrees, $A=48$. I $(\mathrm{I} .267)^{1}=6 \mathrm{I} .6$, and the quantity of cane sugar present at any time $t$ is $A-x=r+48.7(0.267)$, where $r$ is the reading of the solution. The value of $k_{2}$ is taken from Table IV as 0.009 .

TABLe V.-Course of the Incomplete Inversion of CANe Sugar by Invertase

\begin{tabular}{|c|c|c|}
\hline $\begin{array}{l}\text { Time. } \\
\text { Minutes. }\end{array}$ & $\begin{array}{c}\text { Rotation } \\
(r) .\end{array}$ & $k_{1}=\frac{k_{2}}{1-10^{-k_{2} t}} \log \frac{A}{A-x}$ \\
\hline 0 & 48.7 & $\ldots \ldots$ \\
\hline 15 & 44.8 & 0.00094 \\
\hline 30 & $4^{2} \cdot 3$ & I \\
\hline 45 & 40.9 & 0.00087 \\
\hline 60 & 39.9 & 0.00084 \\
\hline 90 & 38.5 & 0.00083 \\
\hline 120 & $37 \cdot 7$ & 0.00083 \\
\hline 240 & 36.0 & 0.00086 \\
\hline \multirow[t]{2}{*}{360} & 35.6 & 0.00094 \\
\hline & & 0.00088 \\
\hline
\end{tabular}
IN 5 O PER CENT. ALCOHOL.

The values of $k_{1}$ in the last column, as calculated from Equation IV, are sufficiently constant to show that the reaction follows the laws that were assumed in the theory, within the limits of the present experimentation. It was found that the activity of the invertase when no alcohol was present was $k_{1}=0.0080$. If this rate in pure water is taken as 100 , the rate in 50 per cent. alcohol is then II. Similar experiments have shown that in 70 per cent. alcohol the rate of inversion, on the basis of 100, is 8 . These values for the activity in 50 and 70 per cent. alcohol are included in Table I.

The Precipitation of Invertase by Alcohol.-Alcohol precipitates inver-

${ }^{1}$ The Clerget factor at $30^{\circ}$; see $J$. Ind. Eng. Chem, 2, 144 (1910). 
tase, and it is in this way possible to prepare a solid enzyme, though nothing regarding its purity can be predicated at present. It is a fact, however, that such solid invertase preparations are usually of low enzymatic activity. The reason for this is apparent from the results of this investigation, for unless the alcoholic precipitation is performed in very strong alcoholic solution, the invertase is rapidly destroyed by the alcohol. There are three ways by which this destruction can be lessened: one is to use strong alcohol in large proportion, another is to work at low temperatures, and the third is to have cane sugar present in the solution to protect the invertase from destruction. In order to test the first method, 5o cc. of invertase liquor which had been dialyzed until it contained only I per cent. of total solids was mixed with $500 \mathrm{cc}$. of 95 per cent. alcohol at $25^{\circ}$, and after half an hour the coagulated precipitate was filtered off, washed with alcohol, then with ether, and dried over sulphuric acid in a desiccator. The mass, which resembled horn in superficial appearance, was dissolved in $50 \mathrm{cc}$. of water, and its inverting activity was found to be 78 per cent. of that of the original sample. The second method of precipitation, at low temperature $\left(0^{\circ}\right)$, gave a small recovery and is not to be recommended.

In order to test the protective action of cane sugar, 25 grams of it were dissolved in $50 \mathrm{cc}$. of dialyzed invertase and 95 per cent. alcohol added until the strength of the mixture became 70 per cent. alcohol. The precipitate was filtered off, washed with ether, and dried in a desiccator. On redissolving, it showed 94 per cent. of the original activity and a second experiment gave a recovery of 96 per cent. These experiments demonstrate that it is possible to precipitate invertase with alcohol without any important loss of activity provided the enzyme is protected by cane sugar. Other sugars may have this protective action also, but this point has not yet been investigated.

\section{Summary.}

O'Sullivan and Tompson's observation that alcohol reduces the activity of invertase is confirmed, and the relation between alcoholic strength and inactivation is shown to be graphically a rounded curve (Fig. I). Alcohol is found to destroy invertase, and the relation between alcoholic strength and rate of destruction is very peculiar, as it shows a high maximum at about 50 per cent. alcohol. The destruction follows the course of unimolecular reactions; it is not noticeable below 20. per cent. alcohol at $30^{\circ}$, is almost instantaneous at 50 per cent., and decreases to nearly zero at 80 per cent. (Fig. 2). If the alcohol contains cane sugar, the destruction is much slower; thus, 6 per cent. cane sugar reduces the rate of destruction in 50 per cent. alcohol from 0.850 to 0.009 , or to about I per cent. of its original value. A mathematical theory of the progress of the inversion of cane sugar by invertase in alcoholic solution of sufficient 
strength to slowly destroy the enzyme has been worked out and its conclusions are found to agree with the results of the experiments. In this way it has been possible to measure the activity of invertase in 50 and 70 per cent. alcohol, where the destruction plays an important role. Invertase can be precipitated by alcohol without much destruction, provided the strength of alcohol in the final solution is high, approximately 90 per cent. By this method of precipitation, working at room temperature, a solid preparation was obtained which had 78 per cent. of the activity of the original solution. If cane sugar is present, invertase can be precipitated with no important destruction by even 70 per cent. alcohol; this method of precipitation gave a recovery of 94 and 96 per cent. of the original activity.

[From the Storrs Agricultural EXPERIMENT Station.]

\section{THE CATALASE OF MOLDS.}

BY ARTHUR W. DOX.

Received June 22, 1910.

An enzyme which accelerates the decomposition of hydrogen peroxide with the liberation of oxygen in a molecular form seems to be almost universally present in living tissues. Its presence in animal organs, in blood, and in milk has been widely investigated. In the vegetable kingdom its occurrence in green plants and in certain fungi is well known.

Many of the basidiomycetes, as well as the yeasts and bacteria, have been found by numerous investigators to contain catalase. The molds, however, have received but little attention with reference to their catalase content. Bach and Chodat ${ }^{1}$ found catalase in Sterigmatocystis nigra, and Pringsheim ${ }^{2}$ noted its presence in the press juice of fifteen out of the seventeen species of mold examined by him. No other investigators seem to have given any attention to the catalase of this important group of fungi.

Catalase is quite distinct from the oxidizing enzymes known as oxidase and peroxidase, though both of these are probably dependent for their oxidizing power upon the presence of some peroxide, either in the plant itself or added in the form of hydrogen peroxide. In the case of the oxidizing enzymes, the oxygen seems to be liberated in a nascent or active form, which readily acts upon oxidizable substances, such as leuco bases, guaiaconic acid, phenolphthalin, etc., and the reaction at once made apparent by the color of the product of oxidation.

Although the molds investigated by the writer showed only slight evidence of oxidase or peroxidase, catalase was generally present in greater concentration. Many of these fungi produce colored spores

${ }^{1}$ Ber., 36, 1756 (1893).

${ }^{2} Z$. physiol. Chem., 62, 386 (1909). 